\title{
The method of scheduling construction projects increasing the use of resources of the general contractor
}

\author{
Michał Tomczak ${ }^{1}$, Piotr Jaśkowski ${ }^{2}$ \\ Department of Construction Methods and Management, Faculty of Civil Engineering and Architecture, \\ Lublin University of Technology, Lublin, Poland \\ E-mail: ${ }^{1}$ m.tomczak@pollub.pl (corresponding author)
}

\begin{abstract}
In carrying out construction projects, enterprises strive to obtain the highest degree of harmonization of the work of the resources involved. It is manifested in ensuring continuous and regular production with a full usage of their executive potential. The purpose of harmonization is to eliminate unjustified interruptions in the work of resources. When planning the realization of non-repetitive construction projects, one should use methods of scheduling that allow the analysis of the project model not only as a function of time. It is also important to take into account the effectiveness of using your own resources and limitations in their availability. The article analyzes the problem of harmonizing the work of crews of the general contractor, performing non-rhythmic, non-cyclical and inhomogeneous processes under the assumption of deterministic operating conditions. An important issue from the point of view of reducing the costs of crews' employment is the continuity of their work. A mathematical model was developed concerning the problem of minimization of downtime in the work of the general contractor crews with a directively fixed time and limit of the project realization cost, taking into account the limitations in the availability of crews and the possibility to outsource works to subcontractors. The possibility of subcontracting works does not allow for a clear indication in the project model sequences of processes carried out by crews and the usage of previously developed scheduling methods. The method of solving the model (in a linear form with continuous and binary variables) is presented in the example. Additionally, the proposed method allows analyzing the impact of the amount of downtime at work on the duration of the project and the impact of the work outsourced to subcontractors on the continuity of the general contractor's work.
\end{abstract}

Keywords: construction project management, project scheduling, renewable resource utilization, schedule optimization, subcontractors' selection.

\section{Introduction}

The traditional approach to the harmonization of construction processes focuses on minimizing the duration of the project and/or the cost of its realization. The classic scheduling methods (network planning methods CPM, PERT, PD) are widely criticized in the literature (Biruk \& Jaśkowski, 2009; Damci, Arditi, \& Polat, 2013; Ammar \& Elbeltagi, 2001; Vanhoucke, 2006; Zhang, Zou, \& Su, 2013; Jaśkowski \& Tomczak, 2017; Tomczak \& Jaśkowski, 2018). The main weaknesses of these methods include (Damci et al., 2013; Ammar \& Elbeltagi, 2001; Zhang et al., 2013; Tomczak, 2014): difficulties in modeling of projects with a large number of processes, disregarding constraints in the availability of resources, complexity of repeatable processes modeling and continuity of processes realization and flow of resources. Due to these imperfections, resource-oriented scheduling methods are developed (Damci et al., 2013) taking into account the limitations in their availability and continuity of work.

Ensuring the continuity of resource work and full utilization of their production potential is the basic intention of methods such as: LOB (Line of Balance) or LSM (Linear Scheduling Method). Dolabi, Afshar, and Abbasnia (2014) extended the CPM/LOB methods for repeatable projects while meeting the predefined completion date of the investment. Harris and Ioannou (1998) developed the RSM method (Repetitive Scheduling Method), which is an extension of the CPM for projects containing repetitive processes. This method makes it possible to take into account technological limitations, ensures continuity of crews operation and allows to identify a controlling sequence of actions that affects the deadline of the entire project realization, which is the equivalent of the critical path in the CPM method. This method was extended to the Fuzzy Repetetive Scheduling Method (F-RSM) by Maravas and Pantouvakis (2010). This development makes it possible to take into account uncertainty in the schedule, differences in the size of working

(C) 2019 Authors. Published by VGTU Press. This is an open-access article distributed under the terms of the Creative Commons Attribution (http://creativecommons.org/licenses/by/4.0/) License, which permits unrestricted use, distribution, and reproduction in any medium, provided the original author and source are credited. 
units or performance variants of crews. An alternative algorithm for identifying the control sequence while continuous realization of processes was developed by Ammar and Elbeltagi (2001). W. Wang, X. Wang, Ge, and He (2013) developed a mathematical model of resource allocation for the realization of repetitive processes, taking into account the limitations in their accessibility and the condition of continuity of their employment. Because the analyzed problem is NP-hard, the authors used a genetic algorithm to solve the model. The algorithm of minimizing downtime of crews performing repetitive processes was proposed by Vanhoucke (2006). Also, the approach presented in Nassar (2005) allows minimizing the downtime of crews work along with the simultaneous optimization of the duration of a repetitive project. Altuwaim and El-Rayes (2018) also dealt with the improvement of the work organization of working crews in repetitive projects, their problem model allows the interruption of selected processes to increase the continuity of crews' work. The reduction of realization time of repetitive project while keeping the continuity of the work of the crews was considered in the work of Bakry, Moselhi, and Zayed (2014). Increasing the continuity of crews' work in repetitive projects can also be achieved by taking into account the learning-forgetting effect (Biruk \& Rzepecki, 2017; Rzepecki \& Biruk, 2018). The authors have developed a simulation program for planning repetitive processes realized in random conditions to determine the impact of learning-forgetting effect for the duration of the project and the break from work of crews.

When planning the realization of non-repetetive construction projects, network planning methods are commonly used. Nowicki (1981) presented a method of analyzing network models (setting the deadlines for realization) ensuring continuity of works at a fixed deadline of the project. He distinguished two types of events in the model: fulfilling the condition of precedence, and precedence and continuity. Vanhoucke and Debels (2007) proposed a different approach enabling to minimize breaks on the patch for which continuity of realization is pursued. For this purpose, at the beginning and at the end of each such path (consisting of processes that can be implemented with various technological and organizational variants) they introduced two artificial activities connected with the start and end point of the network. Extending the time of artificial activities causes - at the directively fixed date of the project - reduction of breaks on a continuous patch. The idea of artificial activities was used by Biruk and Jaśkowski (2009) in order to seek a trade-off between the time of the project realization and the time of interruptions in the realization of detailed organizational sequences by the work crews. While Tang, Sun, Liu, and Wang (2018) proposed a linear project resource leveling model (Line of Balance-based Resource Leveling Model, LOBRLM) based on the LOB and constraint programming (CP) techniques. The LOBRLM comply with synchronized scheduling of activities and leveling allocation of resources without the need to specify a fixed schedule.

Since the harmonization of the work of crews and working crews is a key issue of the construction projects engineering (Tang, Liu, \& Sun, 2014; Georgy, 2008; Biruk \& Jaśkowski, 2009; Jaśkowski \& Tomczak, 2015), there are many studies and papers on this subject. However, most of them concern the scheduling of projects consisting of repetitive processes and does not take into account the possibility of subcontracting (although according to research of Grasso, Rasdorf, and Bridgers (2008) even 76.1\% of construction processes are outsourced to realization to other parties by the general contractors).

In the article, a linear programming model for a non-repetetive construction projects was developed, ensuring minimization of breaks in the general contractor crews' work including restrictions on the availability of contractors and the possibility of outsourcing the realization of processes to subcontractors. The option of subcontracting works does not allow on the planning stage for a clear and direct indication in the project model of the sequence of processes carried out by available crews and the application of so far developed scheduling methods.

\section{Mathematical model of the problem of minimizing downtime of GC crews}

Construction project is modeled using a network prepared with an activity-on-node technique (AON). The scope of the project (division into packages or individual processes - positions in the schedule) and sequence relationships are presented by a graph, with one start and end point, in which $V=\{1,2, \ldots, n\}$ is a set of processes, while graph arcs $E \subset V \times V$ reflect the sequence relations between processes.

To realization of the project there can be involved contractors (or crews) from the set $R$ including $R_{G C}$ subset of general contractor's crews and $R_{S}$ subset of subcontractors. For each process $j \in V$ the set $R_{j} \subset R$ is defined containing available contractors. For each contractor $r \in R$ a set of processes $V_{r} \subset V$ can be specified, realization of which he can be assigned to. Contractor $r \in R_{j}$ will realize the process $j$ at the time $t_{j, r} \in N$ with the cost $k_{j, r} \in R^{+}$. Variables $s_{j}, \forall j \in V$, indicate the start dates of processes. Decisions on the selection of contractors for the realization of processes are modeled using binary variables $x_{j, r} \in\{0,1\}$. Variable $x_{j, r}$ will take the value 1 , when the process $j$ will be realized by the contractor $r$, and the value 0 otherwise.

Some contractors may realize several processes (work packages), but not simultaneously. For this reason, for each contractor $r \in R$ a set of process pairs $J_{r} \subset V \times V$ should be specified that meet the following conditions: 
$(u, v) \in J_{r} \Leftrightarrow u \in V_{r} \wedge v \in V_{r} \wedge u<v$ (processes $u$ and $v$ can be realized by the contractor $r$ ) and processes $u$ and $v$ do not stay on one path in the network model. In the case when the realization of process pair $(u, v) \in J_{r}$ the contractor $r$ $\left(x_{u, r}=1 \wedge x_{v, r}=1\right)$ is assigned, these processes cannot be performed simultaneously (in parallel). The order of realization of these processes will be modeled using the binary variables $y_{u, v} \in\{0,1\}$, specified for $\forall(u, v) \in J_{r}$ and for $\forall r \in R$. The variable $y_{u, v}$ will take the value 1 , if the process $u$ will be realized before the process $v$ starts, value 0 in the opposite case.

The selection of process contractors and setting deadlines for their realization will be carried out in a manner ensuring reduction of downtime in the work of crews of the general contractor. The total time of downtime in each crew's work will be calculated as the difference between the start date of work of a given crew in the realization of the analyzed project, completion of its work and the total time of realization of the processes entrusted to it. In order to establish the necessary deadlines, in the model for each GC $r \in R_{G C}$ crew and for each process $j \in V_{r}$ that it can realize, additional variable figures were used:

$$
p_{j, r}=s_{j} \cdot x_{j, r}, \quad \forall r \in R_{G C}, \forall j \in V_{r} .
$$

In the case when the process $j$ will be realized by the crew, variable $p_{j, r}$ will take the value equal to the start date of the process $j$ realization, otherwise the value 0 . Due to the non-linear nature of the dependency (1), in the model it has been replaced by additional linear dependencies, which enabled application of existing linear programming algorithms with lower computational complexity to solve the model.

The model of the issue of selecting the contractors for individual processes and setting deadlines for their realization (with a directively fixed time $T$ and $\operatorname{cost} K$ realization of the project and the agreed limit $K_{g S}$ subcontracted work cost) takes the following form:

$$
\begin{aligned}
& \min P: P=\sum_{r \in R C}\left(z_{r}^{\max }-s_{r}^{\min }-\sum_{j \in V_{r}}\left(t_{j, r} \cdot x_{j, r}\right)\right) ; \\
& D_{j}=\sum_{r \in R_{j}} t_{j, r} \cdot x_{j, r}, \quad \forall j \in V ; \\
& \sum_{r \in R_{j}} x_{j, r}=1, \quad \forall j \in V \\
& s_{1}=0 \\
& s_{i}+D_{i} \leq s_{j}, \quad \forall(i, j) \in E ; \\
& s_{u}+D_{u} \leq s_{v}+M \cdot\left(1-y_{u, v}\right)+M \cdot\left(2-x_{u, r}-x_{v, r}\right), \\
& \forall(u, v) \in J_{r}, \forall r \in R \text {; } \\
& s_{v}+D_{v} \leq s_{u}+M \cdot y_{u, v}+M \cdot\left(2-x_{u, r}-x_{v, r}\right), \\
& \forall(u, v) \in J_{r}, \forall r \in R \text {; } \\
& s_{n}+D_{n} \leq T ; \\
& \sum_{j \in V} \sum_{r \in R_{j}} k_{j, r} \cdot x_{j, r} \leq K \\
& \sum_{j \in V} \sum_{r \in R_{j} \cap R_{S}} k_{j, r} \cdot x_{j, r} \leq K_{g S} \\
& z_{j, r}=p_{j, r}+t_{j, r} \cdot x_{j, r}, \quad \forall r \in R_{G C}, \forall j \in V_{r} ; \\
& s_{j, r} \leq p_{j, r}+M \cdot\left(1-x_{j, r}\right), \quad \forall r \in R_{G C}, \forall j \in V_{r} ; \\
& z_{r}^{\max } \geq z_{j, r}, \quad \forall r \in R_{G C}, \forall j \in V_{r} ;
\end{aligned}
$$




$$
\begin{gathered}
s_{r}^{\min } \leq s_{j, r}, \quad \forall r \in R_{G C}, \quad \forall j \in V_{r} ; \\
p_{j, r} \leq M \cdot x_{j, r}, \quad \forall r \in R_{G C}, \quad \forall j \in V_{r} ; \\
p_{j, r} s_{j}, \quad \forall r \in R_{G C}, \quad \forall j \in V_{r} ; \\
p_{j, r} \geq s_{j}-M\left(1-x_{j, r}\right), \quad \forall r \in R_{G C}, \quad \forall j \in V_{r} ; \\
s_{r}^{\min } \geq 0, \quad \forall r \in R_{G C} ; \\
s_{j} \geq 0, \quad \forall j \in V ; \\
p_{j, r} \geq 0, \quad \forall r \in R_{G C}, \quad \forall j \in V_{r} ; \\
x_{j, r} \in\{0,1\}, \quad \forall j \in V, \forall r \in R_{j} ; \\
y_{u, v} \in\{0,1\}, \quad \forall(u, v) \in J_{r}, \forall r \in R,
\end{gathered}
$$

where:

$M$ - a sufficiently large number, $z_{r}^{\max }, s_{r}^{\min }$ - respectively, the maximum deadline for completion and the minimum deadline for starting the realization of the processes entrusted to the contractor $r$; these dates correspond to the dates of completion and start of work of GC crews in the realization of the analyzed project, $z_{j, r}, s_{j, r}-$ auxiliary variables indicating respectively, the date of completion and start of the realization of process $j$ by the crew $r$; these terms take value 0 , when crew $r$ does not realize the process $j$.

Function of the objective (2) minimizes the total downtime of crews' work of the general contractor. By means of Eq. (3), the realization time $D_{j}$ of the process $j$ is calculated - variables of this type have been introduced in order to simplify the dependencies (6) - (9). According to condition (4), each process can be realized by only one contractor. The first process starts at 0 (5). The condition (6) allows to set the dates of starting other processes, taking into account the sequence relationships between the processes modeled with the $G$ graph. The formulas (7) and (8) allow to set the start dates of $(u, v) \in J_{r}$ processes that cannot be realized in parallel by the same contractor. If the same contractor $r\left(x_{u, r} \cdot x_{v, r}=0\right)$ will not be assigned to realization of those processes, then the conditions (7) and (8) are always met and these processes can be carried out simultaneously. Otherwise, if the variable $y_{u, v}$ takes the value 1 , then according to condition (7) the process $v$ can only start after completion of the process $u$ (condition (8) will always be met). If the variable $y_{u, v}$ takes the value 0 , then according to condition (8) the process $v$ must end before the start of the process $u$ (condition (7) will always be met). The component $M \cdot\left(2-x_{u, r}-x_{v, r}\right)$ takes the value 0 only if $x_{u, r}=1 \wedge x_{v, r}=1$, so when both the process $u$ and $v$ will be realized by the contractor $r$. The time and cost of the realization of the project cannot exceed the amounts (9) and (10) directively established, and the costs of the work realization by subcontractors cannot exceed the agreed limit cost (11). Dependencies (12) - (15) are used to set the dates of start and completion of the work of the general contractor's crews during the realization of the project. Although the dependencies (14) and (15) have the form of inequality, they allow to determine the wanted extreme values due to the form of the objective function (the maximum deadline for completion of the crew's work is minimized in the objective function and the minimum start date is maximized). Conditions (16) - (18) and (21) were introduced to the model to linearize the dependency (1). If variable $x_{j, r}=1$, then the variable $p_{j, r} \quad$ (according to dependency (17) and (18)) will take the value $s_{j}\left(p_{j, r} \leq s_{j} \wedge p_{j, r} \geq s_{j}\right)$. Otherwise, the value $0-$ according to the dependency (16) $p_{j, r} \leq 0$ and dependency (21) $p_{j, r} \geq 0$. Dependencies (19) - (23) are the boundary conditions of the model.

\section{Calculation example and results}

The developed approach of selecting subcontractors and scheduling their work was used to allocate GC crews and subcontractors of an exemplary construction project. The analyzed project includes the construction of the following facilities of logistics center: a warehouse, training and conference center and a kitchen building. The project is realized in the general contracting system.

The graph of sequence relationships between individual processes (work packages) is shown in Figure 1. Table 1 summarizes the times and costs of realization of individual processes by subcontractors (assessed positively at the 
prequalification stage) and GC crews, determined on the basis of GC estimates and subcontractors' offers. Some contractors may realize several work packages. Table 2 details the element of non-empty sets $J_{r}$ of process pairs that can be realized by the same contractor and that do not stay on the same path in the graph.

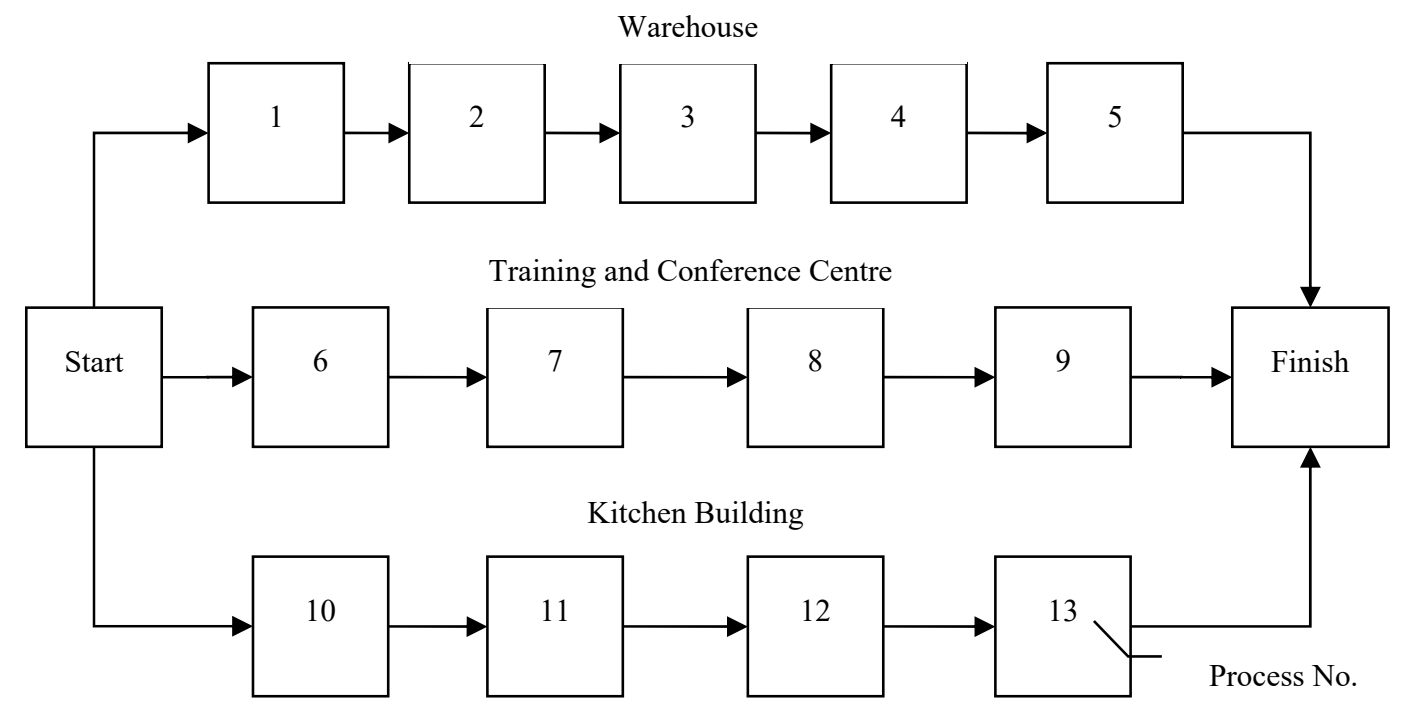

Figure 1. Graph of the project

Table 1. Data for example

\begin{tabular}{|c|c|c|c|c|c|}
\hline No & Process & Construction & $\begin{array}{c}\text { Subcontractor / } \\
\text { GC crew }\end{array}$ & $\begin{array}{l}\text { Realization time } \\
\text { [days] }\end{array}$ & $\begin{array}{c}\text { Realization cost } \\
\text { [1000 PLN] }\end{array}$ \\
\hline \multirow{3}{*}{1} & \multirow{3}{*}{ Groundwork } & \multirow{15}{*}{ Warehouse } & A & 20 & 90 \\
\hline & & & $\mathrm{B}$ & 18 & 110 \\
\hline & & & GC-1 & 17 & 100 \\
\hline \multirow{3}{*}{2} & \multirow{3}{*}{ Foundations } & & $\mathrm{C}$ & 25 & 100 \\
\hline & & & $\mathrm{D}$ & 20 & 120 \\
\hline & & & GC-2 & 20 & 110 \\
\hline \multirow{3}{*}{3} & \multirow{3}{*}{ Reinforced concrete structure } & & $\mathrm{C}$ & 45 & 150 \\
\hline & & & $\mathrm{D}$ & 40 & 160 \\
\hline & & & GC-2 & 42 & 155 \\
\hline \multirow{3}{*}{4} & \multirow{3}{*}{ Steel structure } & & $\mathrm{E}$ & 42 & 300 \\
\hline & & & $\mathrm{F}$ & 40 & 330 \\
\hline & & & GC-3 & 40 & 310 \\
\hline \multirow{3}{*}{5} & \multirow{3}{*}{ Roof } & & G & 35 & 250 \\
\hline & & & $\mathrm{H}$ & 33 & 250 \\
\hline & & & I & 30 & 270 \\
\hline \multirow{3}{*}{6} & \multirow{3}{*}{ Groundwork } & \multirow{9}{*}{ Office building } & A & 12 & 50 \\
\hline & & & $\mathrm{B}$ & 10 & 55 \\
\hline & & & GC-1 & 11 & 52 \\
\hline \multirow{3}{*}{7} & \multirow{3}{*}{ Foundations } & & $\mathrm{C}$ & 15 & 49 \\
\hline & & & $\mathrm{D}$ & 12 & 55 \\
\hline & & & GC-2 & 14 & 50 \\
\hline \multirow{3}{*}{8} & \multirow{3}{*}{$\begin{array}{l}\text { Reinforced concrete structure and } \\
\text { walls }\end{array}$} & & $\mathrm{C}$ & 25 & 70 \\
\hline & & & $\mathrm{D}$ & 30 & 65 \\
\hline & & & GC-2 & 33 & 72 \\
\hline
\end{tabular}


End of Table 1

\begin{tabular}{|c|c|c|c|c|c|}
\hline No & Process & Construction & $\begin{array}{l}\text { Subcontractor / } \\
\text { GC crew }\end{array}$ & $\begin{array}{c}\text { Realization time } \\
\text { [days] }\end{array}$ & $\begin{array}{c}\text { Realization cost } \\
\text { [1000 PLN] }\end{array}$ \\
\hline \multirow{3}{*}{9} & \multirow{3}{*}{ Flat roof } & & G & 19 & 100 \\
\hline & & & $\mathrm{H}$ & 15 & 100 \\
\hline & & & $\mathrm{I}$ & 17 & 90 \\
\hline \multirow{3}{*}{10} & \multirow{3}{*}{ Groundwork } & \multirow{12}{*}{$\begin{array}{l}\text { Pump room and } \\
\text { tank }\end{array}$} & A & 10 & 35 \\
\hline & & & $\mathrm{B}$ & 9 & 40 \\
\hline & & & GC-1 & 8 & 38 \\
\hline \multirow{3}{*}{11} & \multirow{3}{*}{ Foundations } & & $\mathrm{C}$ & 7 & 33 \\
\hline & & & $\mathrm{D}$ & 7 & 38 \\
\hline & & & GC-2 & 6 & 35 \\
\hline \multirow{3}{*}{12} & \multirow{3}{*}{ Reinforced concrete structure } & & $\mathrm{C}$ & 12 & 50 \\
\hline & & & $\mathrm{D}$ & 14 & 52 \\
\hline & & & GC-2 & 10 & 53 \\
\hline \multirow{3}{*}{13} & \multirow{3}{*}{ Roof } & & G & 10 & 60 \\
\hline & & & $\mathrm{H}$ & 12 & 58 \\
\hline & & & I & 8 & 55 \\
\hline
\end{tabular}

Table 2. Elements of non-empty sets $J_{r}$

\begin{tabular}{|c|c|}
\hline $\begin{array}{c}\text { Subcontractor GC } \\
\text { crew } r\end{array}$ & $(u, v) \in J_{r}$ \\
\hline A & $(1,6) ;(1,10) ;(6 ; 10)$ \\
\hline B & $(1,6) ;(1,10) ;(6 ; 10)$ \\
\hline C & $(2,7) ;(2,8) ;(2,11) ;(2,12) ;(3,7) ;(3,8) ;(3,11) ;(3,12) ;(7,11) ;(7,12) ;(8,11) ;(8,12)$ \\
\hline D & $(2,7) ;(2,8) ;(2,11) ;(2,12) ;(3,7) ;(3,8) ;(3,11) ;(3,12) ;(7,11) ;(7,12) ;(8,11) ;(8,12)$ \\
\hline G & $(5,9) ;(5,13) ;(9,13)$ \\
\hline H & $(5,9) ;(5,13) ;(9,13)$ \\
\hline I & $(5,9) ;(5,13) ;(9,13)$ \\
\hline GC-1 & $(1,6) ;(1,10) ;(6 ; 10)$ \\
\hline GC-2 & $(2,7) ;(2,8) ;(2,11) ;(2,12) ;(3,7) ;(3,8) ;(3,11) ;(3,12) ;(7,11) ;(7,12) ;(8,11) ;(8,12)$ \\
\hline
\end{tabular}

The minimum cost of realization (with unlimited duration and the border cost of subcontracted works) is PLN 1,317,000 (realization time 194 days, the cost of commissioned works PLN 1,317,000). None of the GC crews has been assigned to realization of the project.

The minimum time of the project realization (with unlimited cost and the limited cost of commissioned work) is 147 days. In this solution, the cost of realization amounted to PLN 1,411,000 and the cost of subcontracted works PLN 765,000. In this solution, the GC crews perform the following processes: GC-1 process 1 and 10 (downtime 68 days), GC-2 process 2, 11 and 12 (downtime 73 days), GC-3 crew process 4 . Total downtime is therefore 141 days.

The analysis of the impact of the $T, K$ and $K_{g S}$ amounts provides additional information supporting the decision of $\mathrm{GC}$, e.g. in the preparation of a tender offer.

It was assumed that the duration of the project realization cannot be longer than $T=150$ days, and the cost of subcontracted works should not exceed the $K_{g S}=$ PLN 470,000, and the cost of the project realization should not exceed the amount $\mathrm{K}=\mathrm{PLN} 1,400,000$. The mathematical model of the problem in the example was solved using the LINGO 14.0 Optimization Modeling Software by Lingo Systems Inc.

The schedule for the realization of the project for the optimal solution is presented in Figure 2. In this solution, only processes 5, 9, 10 and 13 are subcontracted. The cost of the subcontracted works is PLN 463,000, the cost of the project realization is PLN 1,400,000 and the realization time is 150 days. GC crews work continuously. 


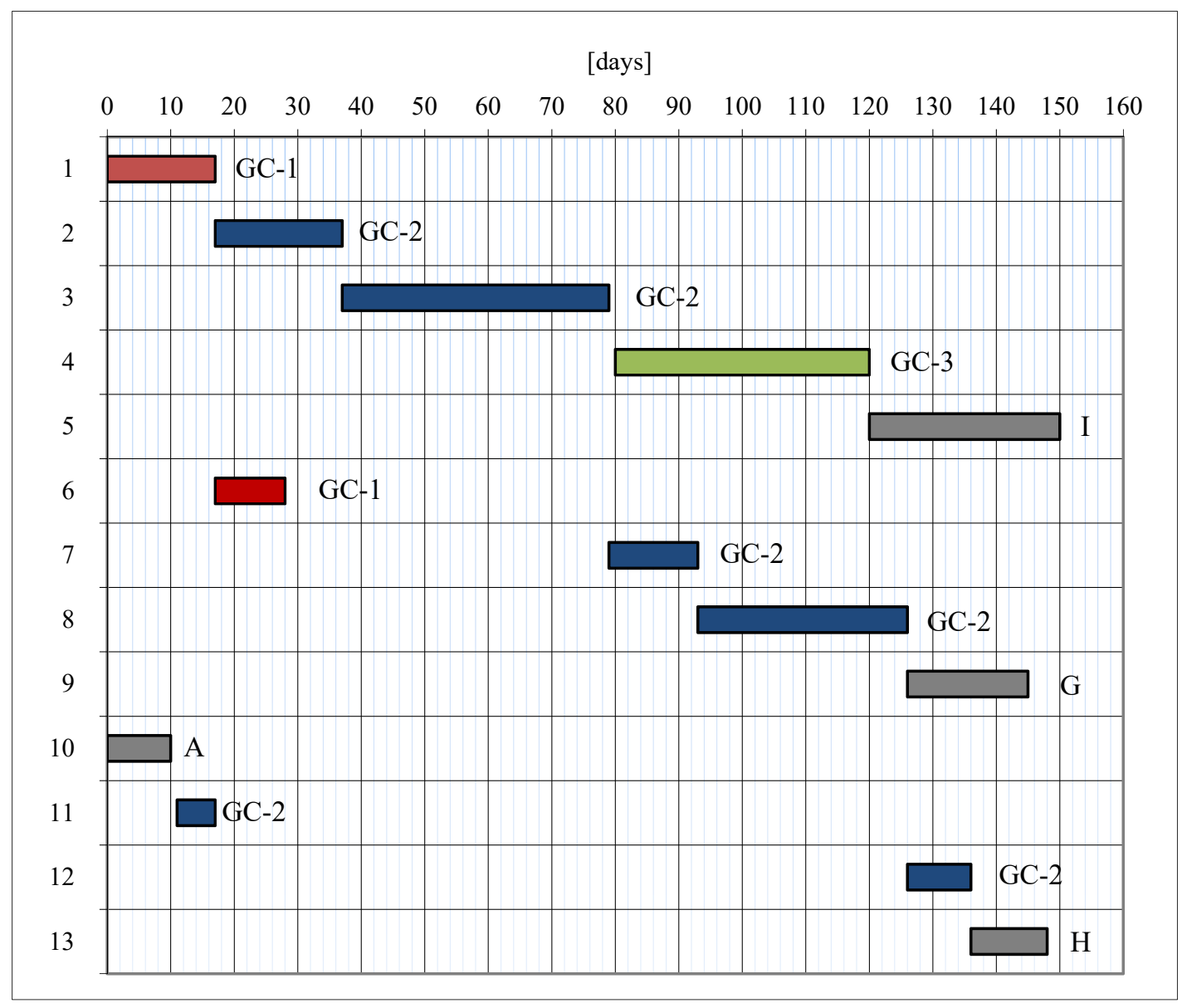

Figure 2. The schedule for the realization of the project - optimal solution for the example

\section{Conclusions}

The problem of ensuring the continuity of crews' work realizing non-repetetive projects is important primarily from the point of view of reducing the costs of employment of crews of the general contractor. When designing the realization of non-repetetive construction projects, there should be therefore used scheduling methods that allow the analysis of the project model not only as a function of time. It is also important to take into account the effectiveness of using own resources and restrictions in their accessibility and the need to cooperate with other enterprises when making orders and their realization. General contracting is one of the most popular systems for realization of a construction project in Poland. Subcontractors are usually able to realize specialized construction works faster and with a lower cost than the general contractor. Ordering works to subcontractors, not only for specialist works, but also for the need to complete the project on a fixed date with limited employment of your own resources, is nowadays a common practice. The mathematical model proposed in the article makes it possible to set a schedule of works and also to select contractors for particular processes from among GC resources and available subcontractors. At the same time, it allows you to increase the use of your own general contractor's resources. Due to the linear form of the model's dependency, it can be solved using commercially available software.

\section{Acknowledgements}

The work was financed by the Polish Ministry of Science and Higher Education S/63/2019.

\section{References}

Altuwaim, A., \& El-Rayes, K. (2018). Minimizing duration and crew work interruptions of repetitive construction projects. Automation in Construction, 88, 59-72. https://doi.org/10.1016/j.autcon.2017.12.024

Ammar, M. A., \& Elbeltagi, E. (2001). Algorithm for determining controlling path considering resource continuity. Journal of Computing in Civil Engineering, 15(4), 292-298. https://doi.org/10.1061/(ASCE)0887-3801(2001)15:4(292) 
Bakry, I., Moselhi, O., \& Zayed, T. (2014). Optimized acceleration of repetitive construction projects. Automation in Construction, 39, 145-151. https://doi.org/10.1016/j.autcon.2013.07.003

Biruk, S., \& Jaśkowski, P. (2009). The work continuity constraints problem in construction projects' network models. Archives of Civil Engineering, 55(1), 29-41.

Biruk, S., \& Rzepecki, Ł. (2017). Wpływ zjawiska uczenia i zapominania na czas realizacji powtarzalnych procesów budowlanych realizowanych w warunkach losowych. Przegląd Naukowy Inżynieria i Ksztaltowanie Środowiska, 26(2), 202-209. https://doi.org/10.22630/PNIKS.2017.26.2.18

Damci, A., Arditi, D., \& Polat, G. (2013). Resource leveling in line of balance scheduling. Computer Aided Civil and Infrastructure Engineering, 28(9), 679-692. https://doi.org/10.1111/mice.12038

Dolabi, H. R. Z., Afshar, A., \& Abbasnia, R. (2014). CPM/LOB scheduling method for project deadline constraint satisfaction. Automation in Construction, 48, 107-118. https://doi.org/10.1016/j.autcon.2014.09.003

Georgy, M. E. (2008). Evolutionary resource scheduler for linear projects. Automation in Construction, 17(5), 573-583. https://doi.org/10.1016/j.autcon.2007.10.005

Grasso, B., Rasdorf, W., \& Bridgers, M. (2008). Nature and extent of domestic construction program outsourcing. Journal of Construction Engineering and Management, 134(12), 10021010. https://doi.org/10.1061/(ASCE)0733-9364(2008)134:12(1002)

Harris, R. B., \& Ioannou, P. G. (1998). Scheduling Projects with Repeating Activities. Journal of Construction Engineering and Management, 124(4), 269. https://doi.org/10.1061/(ASCE)0733-9364(1998)124:4(269)

Jaśkowski, P., \& Tomczak, M. (2015). Assignment problem and its extensions for construction project scheduling. Czasopismo Techniczne Budownictwo, Zeszyt 2-B (6), 241-248.

Jaśkowski, P., \& Tomczak, M. (2017). Problem minimalizacji przestojów w pracy brygad generalnego wykonawcy w harmonogramowaniu przedsięwzięć budowlanych. Przegląd Naukowy Inżynieria i Kształtowanie Środowiska, 26(2), $193-201$. https://doi.org/10.22630/PNIKS.2017.26.2.17

Maravas, A., \& Pantouvakis, J. P. (2010). Fuzzy repetitive scheduling method for projects with repeating activities. Journal of Construction Engineering and Management, 137(7), 561-564. https://doi.org/10.1061/(ASCE)CO.1943-7862.0000319https://doi.org/561-564. 10.1061/(ASCE)CO.1943-7862.0000319

Nassar, K. (2005). Evolutionary optimization of resource allocation in repetitive construction schedules. Journal of Information Technology in Construction (ITcon), 10(18), 265-273.

Nowicki, K. (1981). Organizacja i ekonomika budowy. Wrocław: Wydawnictwo PWr.

Rzepecki, Ł., \& Biruk, S. (2018). Simulation method for scheduling linear construction projects using the learning-forgetting effect. In MATEC Web of Conferences (vol. 219, p. 04007). EDP Sciences. https://doi.org/10.1051/matecconf/201821904007

Tang, Y., Liu, R., \& Sun, Q. (2014). Schedule control model for linear projects based on linear scheduling method and constraint programming. Automation in Construction, 37, 22-37. https://doi.org/10.1016/j.autcon.2013.09.008

Tang, Y., Sun, Q., Liu, R., \& Wang, F. (2018). Resource leveling based on line of balance and constraint programming. Computer-Aided Civil and Infrastructure Engineering, 33(10), 864-884. https://doi.org/10.1111/mice.12383

Tomczak, M. (2014). Model decyzyjny dostaw realizowanych przez centrum dystrybucyjne dla potrzeb małych i średnich przedsiębiorstw budowlanych. Logistyka, (3), 6358-6366.

Tomczak, M., \& Jaśkowski, P. (2018). Application of type-2 interval fuzzy sets to contractor qualification process. KSCE Journal of Civil Engineering, 22(8), 2702-2713. https://doi.org/10.1007/s12205-017-0431-2

Vanhoucke, M. (2006). Work continuity constraints in project scheduling. Journal of Construction Engineering and Management, 132(1), 14-25. https://doi.org/10.1061/(ASCE)0733-9364(2006)132:1(14)

Vanhoucke, M., \& Debels, D. (2007). The discrete time/cost trade-off problem: Extensions and heuristic procedures. Journal of Scheduling, 10(4-5), 311-326. https://doi.org/10.1007/s10951-007-0031-y

Wang, W., Wang, X., Ge, X., \& He, Y. (2013). Resource continuity constraints in repetitive project scheduling. Journal of Information \& Computational Science, 10(17), 5619-5628. https://doi.org/10.12733/jics20103542

Zhang, L., Zou, X., \& Su, Z. (2013). GA optimization model for time/cost trade off problem in repetitive projects considering resource continuity. Applied Mathematics \& Information Sciences, 7(2), 611-617. https://doi.org/10.12785/amis/070226 